\title{
In vitro evaluation of the effects of graphene platelets on glioblastoma multiforme cells
}

This article was published in the following Dove Press journal:

International Journal of Nanomedicine

23 January 2013

Number of times this article has been viewed

\author{
Sławomir Jaworski' \\ Ewa Sawosz' \\ Marta Grodzik' \\ Anna Winnicka² \\ Marta Prasek' \\ Mateusz Wierzbicki \\ André Chwalibog ${ }^{3}$ \\ 'Division of Biotechnology and \\ Biochemistry of Nutrition, Faculty \\ of Animal Science, ${ }^{2}$ Department \\ of Pathology and Veterinary \\ Diagnostics, Faculty of Veterinary \\ Medicine, Warsaw University \\ of Life Sciences, Warsaw, Poland; \\ ${ }^{3}$ Department of Veterinary Clinical \\ and Animal Sciences, University \\ of Copenhagen, Copenhagen, \\ Denmark
}

\begin{abstract}
Graphene is a single atom-thick material with exciting potential. It can be used in many fields, from electronics to biomedicine. However, little is known about its toxicity and biocompatibility. Herein, we report a study on the toxicity of graphene platelets (GPs) by examining the influence of GPs on the morphology, mortality, viability, membrane integrity, and type of cell death of U87 and U118 glioma cells. It was found that graphene is toxic to glioma cells, but it activated apoptosis only in the U118 cell line, without inducing necrosis, indicating the potential applicability of GP in anticancer therapy.
\end{abstract}

Keywords: toxicity, glioma, apoptosis

\section{Introduction}

Glioblastoma multiforme, which originates from astroglial cells, is the most common brain tumor and has the highest degree of malignancy. ${ }^{1}$ It is characterized by infiltrative growth, intensive migration, and fast spread in brain tissues. ${ }^{2}$ Infiltration occurs along nerve fibers, blood vessels, via mater, and somata. Complete surgical resection of the glioma is impeded by this type of tumor growth, which is the reason for tumor recurrence and the necessity for chemotherapy. There are new experimental strategies for the treatment of glioma, especially regarding the mechanisms related to programmed cell death, ${ }^{3,4}$ that are raising hopes in cancer treatment. However, even the best drugs have strong negative effects on healthy cells and are distributed within the organism in an uncontrolled way. Thus, researchers are searching for apoptotic agents capable of targeting and destroying tumor tissue without any translocation to other cells.

Recently, new biologically active substances such as nanoparticles have been found to be useful in anticancer therapy. Many studies have shown that nanomaterials may have a positive effect on health, including through use in cancer treatment; ${ }^{5-7}$ however, some are still not well understood. For instance, there is a general lack of information about the recently developed substance "graphene."

Graphene is one of the carbon allotropes and is regarded as the thinnest material in the world. ${ }^{8} \mathrm{~A}$ unique property of a graphene sheet is the ratio of its thickness to the size of its surface, which distinguishes this material from all other known nanomaterials. Graphene flakes may be similar to or greater in size than cells. This limits their mobility within tissues as well as their consumption by phagocytic cells. Further, graphene has unique physicochemical properties. A key feature is that its electrons move at very high speed ${ }^{8}$ and have different biological impacts on various cell and tissue types. As the charge of graphene may interfere with cell membranes by adhesion and by bonding
Correspondence: André Chwalibog University of Copenhagen, Department of Veterinary Clinical and Animal Sciences, Groennegaardsvej 3, I 870 Frederiksberg, Denmark

Tel +4535333044

$\mathrm{Fax}+4535333020$

Email ach@sund.ku.dk 
with cell receptors, it may block the supply of nutrients, induce stress, and activate apoptotic mechanisms in cancer cells. In addition, graphene has two active parts - surfaces and edges - so its edges can attach to biological molecules and its surfaces can adhere to cells.

Recently, investigations have studied the effects of functionalized graphene materials on living organisms. It has been demonstrated that both surface chemistry and size play key roles in controlling the biodistribution, toxicity, and excretion of graphene and, therefore, different graphene materials may have different effects on the organism. ${ }^{9}$ The majority of the studies have focused on graphene oxide, ${ }^{9}$ which is produced by chemical methods; however, to the authors' knowledge, there have been no biological studies of graphene platelets (GPs), which are produced by physical methods - that is, by direct exfoliation of graphite, without the initial stage of oxidation. The reduced GPs are hydrophobic, while graphene oxide is well dispersed in water, forming stable hydrocolloids. Given that GPs have specific physicochemical properties that differ from those of other graphene materials, we predicted that GPs might have different cellular toxicity.

We achieved promising results in our previous studies of diamond hydrophobic nanoparticles in glioma therapy. ${ }^{6}$ In the present research, we hypothesized that GPs also have a toxic influence on glioma cells. The properties of glioma cells may vary depending on the cell line. In our study, two different human cell lines were used: U87 and U118. These lines are characterized by different morphology, activity of genes involved in cell-cycle regulation, and susceptibility to programmed cell death. ${ }^{10}$ The objective of the present study was to evaluate the toxicity of GPs as well as the pro-apoptotic and necrotic activities of graphene on tumor cells.

\section{Materials and methods}

\section{Preparation and characterization of GPs}

Graphene powder (purity $>99.99 \%$ ) was purchased from SkySpring Nanomaterials (Houston, TX, USA). The powder was dispersed in ultrapure water to prepare a $1.0 \mathrm{mg} / \mathrm{mL}$ solution. After 30 minutes of sonification, the solution was diluted to different concentrations with $1 \times$ Dulbecco's modified Eagle's culture medium (Sigma-Aldrich, St Louis, MO, USA) immediately prior to exposure to cells.

The shape and size of the graphene sheets were inspected using a JEM-1220 (JEOL, Tokyo, Japan) transmission electron microscope (TEM) at $80 \mathrm{KeV}$, with a Morada eleven-megapixel camera (Olympus Soft Imaging Solutions, Münster, Germany). Samples for the TEM were prepared by placing droplets of hydrocolloids on to Formvar-coated copper grids (Agar Scientific, Stansted, UK). Immediately after drying of the droplets in dry air, the grids were inserted into the TEM. The test was performed in triplicate.

The zeta potential in water was measured using a Zetasizer Nano ZS model ZEN3500 (Malvern Instruments, Malvern, UK).

\section{Cell cultures and treatments}

Human glioblastoma U87 and U118 cell lines were obtained from the American Type Culture Collection (Manassas, VA, USA) and maintained in Dulbecco's modified Eagle's culture medium supplemented with $10 \%$ fetal bovine serum (Sigma-Aldrich), 1\% penicillin, and streptomycin (SigmaAldrich) at $37^{\circ} \mathrm{C}$ in a humidified atmosphere of $5 \% \mathrm{CO}_{2} / 95 \%$ air in a NuAire DH AutoFlow $\mathrm{CO}_{2}$ Air-Jacketed Incubator (Plymouth, MN, USA).

\section{Cell morphology}

U87 and U118 cells were plated in six-well plates $\left(1 \times 10^{5}\right.$ cells per well) and incubated for 24 hours. Cells cultured in medium without the addition of GPs were used as the control. Graphene was introduced to the cells at increasing concentrations $(5,10,20,50$, and $100 \mu \mathrm{g} / \mathrm{mL})$. Cell morphology was recorded using an optical microscope at 24 hours post-exposure.

\section{Cell mortality}

Cell mortality was evaluated by Trypan blue assay (SigmaAldrich). U87 and U118 cells were plated in six-well plates $\left(5 \times 10^{5}\right.$ cells per well $)$ and incubated for 24 hours. After this, the medium was removed and GPs were introduced to the cells at increasing concentrations in the culture medium. Cells cultured without GPs were used as a control. Another 24 hours later, the medium was removed and the cells were detached with $300 \mu \mathrm{L}$ of a trypsin-ethylenediaminetetraacetic acid (EDTA) solution. This mixture was centrifuged at $1200 \mathrm{rpm}$ for 3 minutes. Then, $700 \mu \mathrm{L}$ of Trypan blue solution was added to each well and dispersed. After 5 minutes, the cells were counted using a hemocytometer. Dead cells were stained blue. Cell mortality was expressed as the percentage of the dead cells in proportion to the total cell number.

\section{Cell viability}

The cell viability was evaluated using a 2,3-Bis-(2-methoxy4-nitro-5-sulfophenyl)-2H-tetrazolium-5-carboxyanilide salt (XXT) based cell proliferation assay kit (Life Technologies, Taastrup, Denmark). U87 and U118 were plated in 96-well 
plates $\left(5 \times 10^{3}\right.$ cells per well $)$ and incubated for 24 hours. Then, the medium was removed and GPs were introduced to the cells. In the next step, $50 \mu \mathrm{L}$ of XTT solution was added to each well and incubated for an additional 3 hours at $37^{\circ} \mathrm{C}$. The optical density (OD) of each well was recorded at $450 \mathrm{~nm}$ on an enzyme-linked immunosorbent assay reader (Infinite M200, Tecan, Durham, NC, USA). Cell viability was expressed as the percentage $\left(\mathrm{OD}_{\text {test }}-\mathrm{OD}_{\text {blank }}\right) /$ $\left(\mathrm{OD}_{\text {control }}-\mathrm{OD}_{\text {blank }}\right)$, where "OD $\mathrm{OD}_{\text {test }}$ " is the optical density of cells exposed to GPs, "OD control sample, and "OD blank" is the optical density of wells without glioma cells.

\section{Membrane integrity}

A lactic dehydrogenase (LDH) test (undertaken using an LDH-based in vitro toxicology assay kit, Sigma-Aldrich) was used to evaluate cell membrane integrity. U87 and U118 cells were plated in 96 -well plates $\left(5 \times 10^{3}\right.$ cells per well) and incubated for 24 hours. After this time, the medium was removed and GPs were introduced to the cells. After incubation with GPs, half of the volume of the culture medium was removed. A total of $100 \mu \mathrm{L}$ of the lactate dehydrogenase assay mixture was added to each well. The plate was covered and incubated for 20 minutes at room temperature. The OD was recorded as outlined and the $\mathrm{LDH}$ leakage was expressed as the percentage of OD. The resulting reduced nicotinamide adenine dinucleotide $\left(\mathrm{NADH}^{+}\right)$was utilized in the stoichiometric conversion of a tetrazolium dye. When cell-free aliquots of the medium from cultures given different treatments were assayed, the amount of LDH activity could be used as an indicator of relative cell viability as well as a function of membrane integrity. If the membrane is damaged, intracellular LDH molecules are released into the culture medium. Thus, the LDH level in the medium indicates cell membrane integrity.

\section{Apoptosis assay}

An apoptosis kit (Alexa Fluor ${ }^{\circledR} 488$ Annexin V/Dead Cell Apoptosis Kit with Alexa Fluor 488 Annexin V and propidium iodide (PI) for flow cytometry, Life Technologies) was used to detect apoptotic and necrotic cells. The manufacturer's kit manual was strictly followed. U87 and U118 glioma cells were plated in six-well plates $\left(1 \times 10^{5}\right.$ cells per well) and incubated for 48 hours. After this time, the medium was removed and GPs were introduced to the cells at only one test concentration $(100 \mu \mathrm{g} / \mathrm{mL})$ in the culture medium and incubated for another 24 hours. The positive control was prepared by culturing control cells in medium with $200 \mathrm{mM} \mathrm{H} \mathrm{O}_{2}$ for 30 minutes. U87 and U118 cells were harvested and washed in cold phosphatebuffered saline. Next, the cells were transferred to tubes, centrifuged and suspended in Annexin Binding Buffer, $5 \mu \mathrm{L}$ of Alexa Fluor 488 Annexin $\mathrm{V}$, and $1 \mu \mathrm{L}$ of $100 \mu \mathrm{g} / \mathrm{mL}$ PI working solution were added to each $100 \mu \mathrm{L}$ of the cell suspension. Glioma cells were analyzed by flow cytometry, measuring the fluorescence emission at $530 \mathrm{~nm}$ and $575 \mathrm{~nm}$ (or equivalent) using excitation at $488 \mathrm{~nm}$. The cells were considered positive on the basis of the fluorescence intensity of Annexin V-Alexa Fluor 488 or PI. Positivity to Annexin V-Alexa Fluor 488 indicates the release of the phospholipid phosphatidylserine, which occurs in the early stage of apoptosis. Positivity for PI indicates damage to the cell membrane, which occurs not only in the end stage of apoptosis but also in necrosis. Apoptotic cells were identified as Annexin V-Alexa Fluor $488^{+}$and $\mathrm{PI}^{-}$, non-viable cells as Annexin V-Alexa Fluor $488^{+}$and $\mathrm{PI}^{+}$, and viable cells as Annexin V-Alexa Fluor $488^{-}$and $\mathrm{PI}^{-}$.

\section{Statistical analysis}

Data were analyzed using multifactorial analysis of variance with Statgraphics ${ }^{\circledR}$ Plus 4.1 (StatPoint Technologies, Warrenton, VA, USA). The differences between groups were tested using Tukey's multiple range tests. All mean values are presented with the standard deviation.

\section{Results}

\section{Characterization of GPs}

Figure 1 shows representative TEM images of GPs. Most of the graphene sheets were visible as a single layer or a few layers. Their shape was irregular but rounded rather

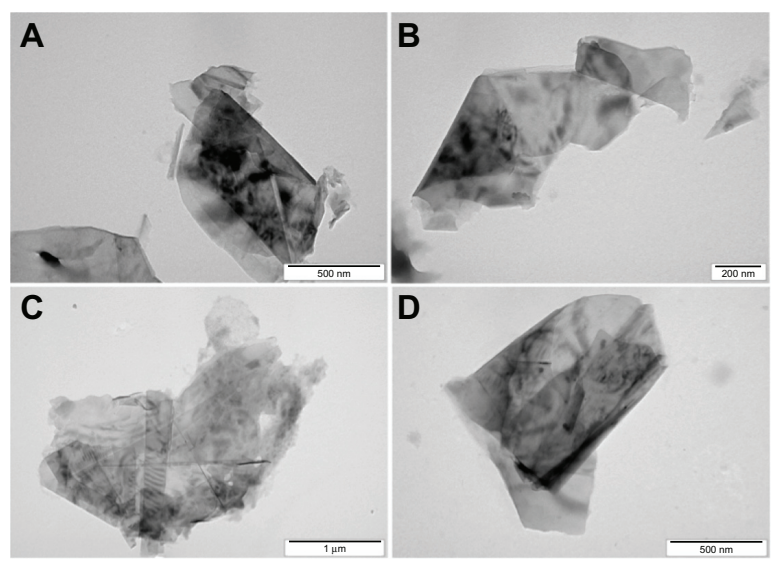

Figure I Characterization of graphene platelet samples (A-D) by transmission electron microscopy. 
than sharp and the flakes were often observed individually but still as separate layers. Diameter of the particles ranged from $450 \mathrm{~nm}$ to $1.5 \mu \mathrm{m}$. The mean zeta potential for the GPs was -9.61 .

\section{Cell morphology}

Both cells lines were characterized by a different morphology and growth rate (Figure 2). U87 cells grew faster and the cells were not only larger and less branched but also had longer protrusions than the U118 cells. The U118 cells were smaller, more compact, and had shorter protrusions than the U87 cells. In both cases, it was noticeable that GP agglomerates attached to the cell body but not to the protrusions. A low number of free agglomerates indicated a high affinity for the studied cells. There was a clear difference between the GP-treated cells and the control cells. The GP-treated cells were more oval, denser, and their protrusions were shorter in comparison with the control cells. In addition, the GPs affected the adhesion of the cells to the plate.

\section{Cell mortality}

The cell mortality was monitored by Trypan blue exclusion assay, in which the dead cells are stained in blue while the living are not stained. Mortality was significantly different between cell lines and GP concentrations. GPs had the highest toxicity at a concentration of $100 \mu \mathrm{g} / \mathrm{mL}$, with mortality
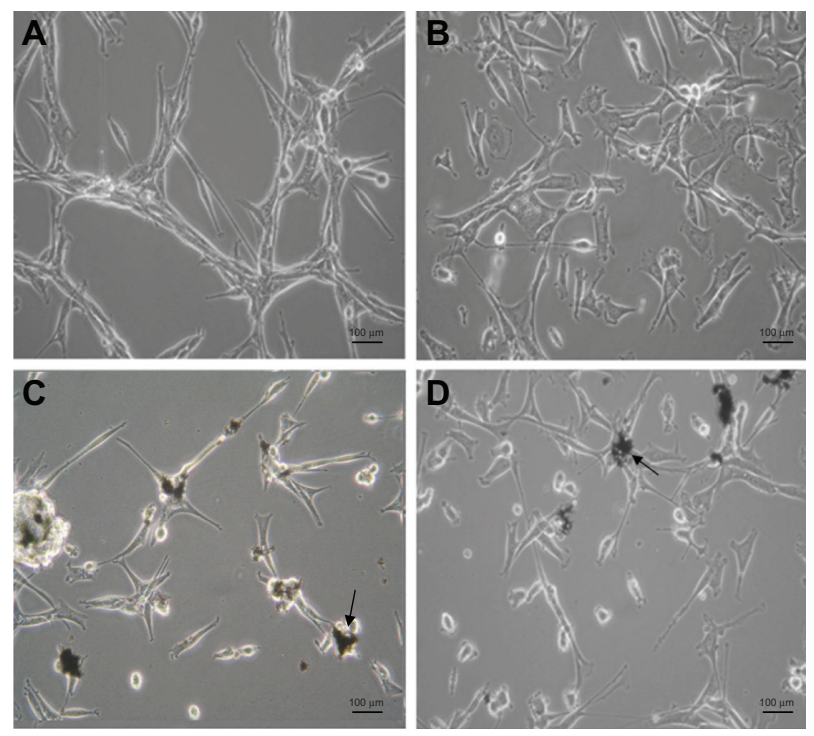

Figure 2 Optical microscopy images of graphene platelet (GP)-treated and untreated U87 and UI 18 glioma cells. (A) U87 control; (B) UII 8 control; (C) GPtreated U87; (D) GP-treated UI I8.

Note: Arrows point to GP agglomerates. of $42 \%$ and $52 \%$ for U87 and U118 cells, respectively (Figure 3).

\section{Cell viability}

The XTT-based cell proliferation assay is based on the ability of metabolically active cells to reduce the tetrazolium salt XTT into the orange-colored compound formazan. The greater the number of active cells in the well, the higher the activity of mitochondrial enzymes and concentration of the dye. The increased concentration of GPs resulted in decreased vitality in both glioma cell types. The lowest vitality was observed at the GP concentration of $100 \mu \mathrm{g} / \mathrm{mL}$, with $54 \%$ and $58 \%$ in U87 and U118 cells, respectively (Figure 4).

\section{Membrane integrity}

If the cell membrane is damaged, intracellular LDH molecules may be released into the culture medium. Thus, the LDH level outside the cells demonstrates the cell membrane integrity. GPs disrupted cell membrane functionality and integrity and there were significant differences between cell lines and GP concentrations (Figure 5). Increased GP concentration led to greater glioma membrane damage, which was higher in U87 than in U118 cells.

\section{Apoptosis assay}

Apoptosis assay provides a simple and effective method for detecting one of the earliest events in apoptosis - the externalization of phosphatidylserine (PS) in living cells. Soon after apoptosis is induced, PS is translocated from the inner leaflet of the plasma membrane to the outer leaflet. This assay uses Annexin V, which has a strong and specific affinity for PS, monitoring the PS translocation due to apoptosis. GPs induced apoptosis and necrosis in U87 and U118 glioma cells (Figure 6). The degree of apoptosis was higher in both glioma cell types (68\% in U87 and 99\% in U118) than in the control group (9.2\% in U87 and 18\% in U118). The degree of necrosis was $24 \%$ in U87 and $1.7 \%$ in the control group, while it was only $0.2 \%$ in U118 cells.

\section{Discussion}

In this study, we evaluated the influence of graphene flakes on the morphology, viability, and mortality of glioblastoma cells. Because the surface of graphene and its functionalization play a key role in the physicochemical characteristics and thereby in the biocompatibility of different graphene materials, ${ }^{11}$ the present results may only be representative for the particular particles used here. Visualization of the GPs showed that the thickness of flakes was characteristic of graphene; that 


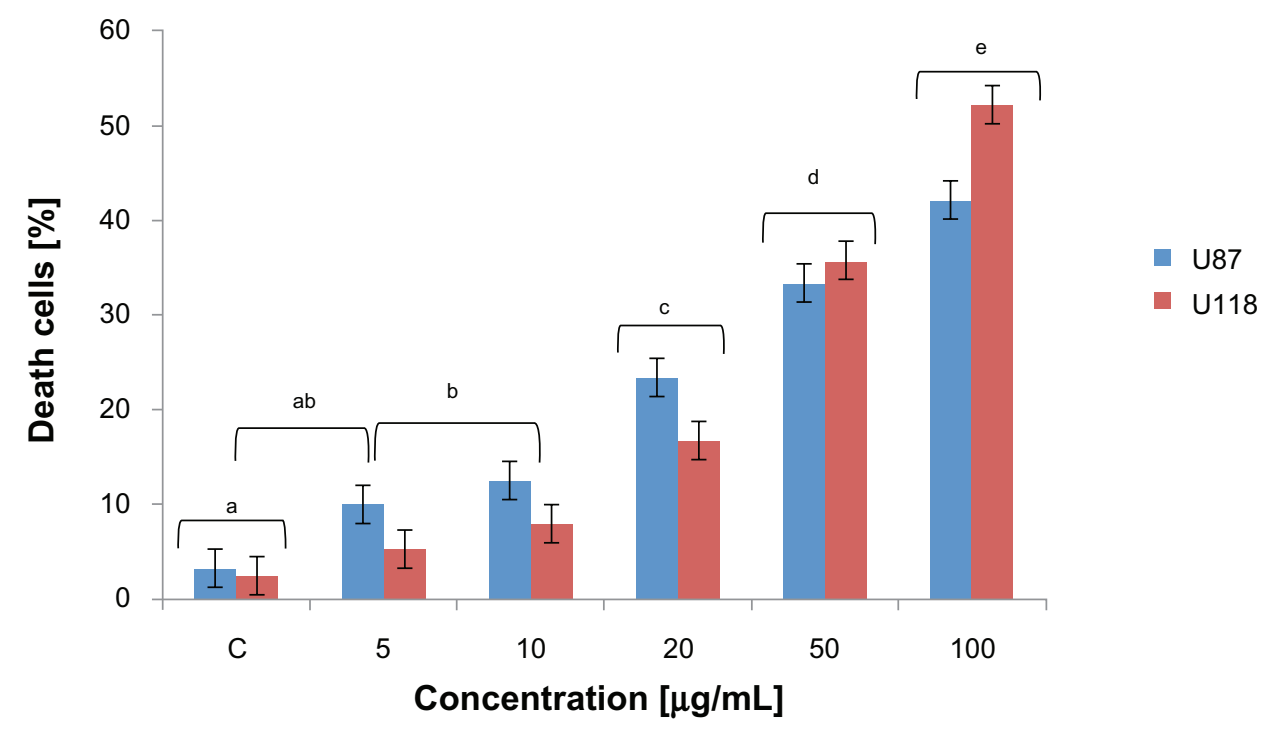

Figure 3 Effect of graphene platelets on the mortality of U87 (blue) and UII8 (red) glioma cells.

Notes: There were no significant differences $(P=0.793)$ between the cell lines. The columns with different letters (a-e) indicate significant differences between the concentrations $(P=0.00 \mathrm{I})$.

Abbreviation: C, control group (untreated cells).

is, extremely thin as one layer of carbon atoms. However, the area of flakes was between $450 \mathrm{~nm}$ and $1.5 \mu \mathrm{m}$, thus not at nanoscale. The large surface area of the flakes did not allow graphene to enter into glioma cells, so GPs were not observed inside the cells. Chang et al $^{12}$ examined the toxicity of graphene oxide on the A549 cell line and, similarly, did not observe the entry of graphene into the cells. However, in our experiments, we noted there was a strong tendency for the graphene flakes to be localized close to the cells, indicating an affinity of graphene for the cells. The same tendency was observed in a study on the influence of graphene on bacterial cells. ${ }^{13}$ In the present study, microscopic images of glioma cells and GP self-organization show that the GPs were adhered to the cells and, moreover, the flakes were usually connected to the cell body, not to its protrusions. This observation indicates a direct interaction between the GPs and cells caused by their chemical or/and physical properties. Furthermore, it indicates that this effect might depend on the morphology of the cells, especially the number and the shape of protrusions.

Assessment of cell viability showed a toxic influence of GPs on glioma cells. Using a concentration of $100 \mu \mathrm{g} / \mathrm{mL}$ resulted in a survival rate of $54 \%$ in U87 cells and $60 \%$ in the U118 line. A similar result could be observed in the mortality test, as the same concentration caused death in $42 \%$ of U87 cells

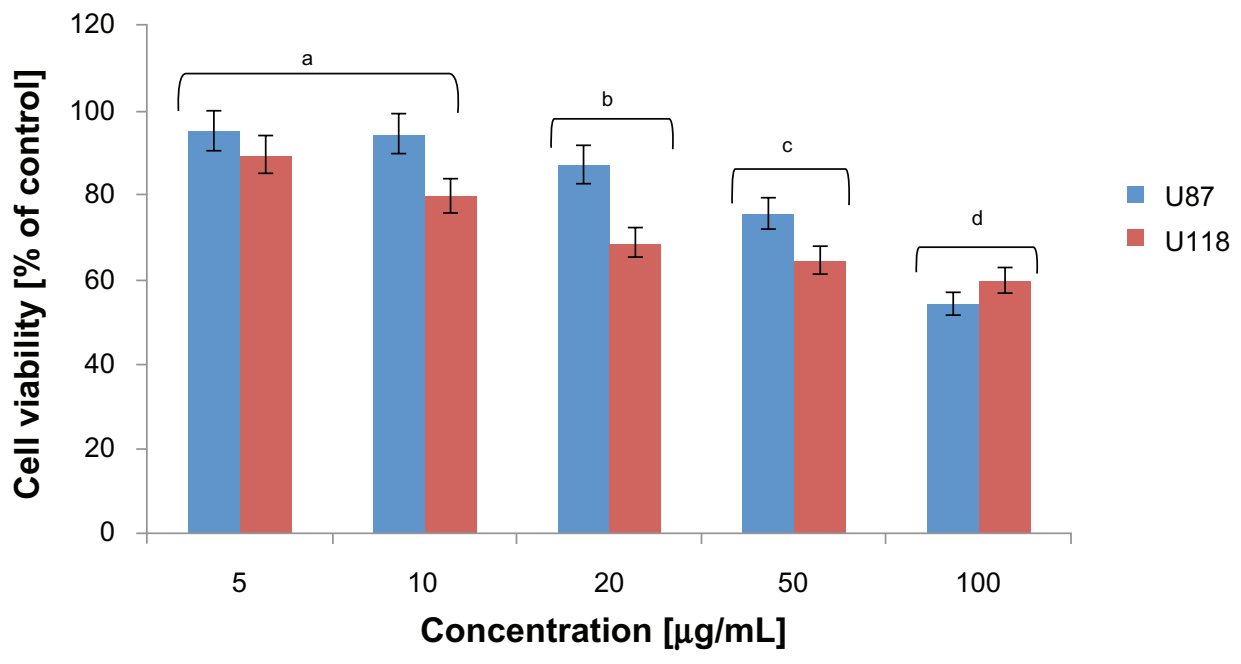

Figure 4 Effect of graphene platelets on the viability of U87 (blue) and UII 8 (red) glioma cells.

Notes: There were no significant differences $(P=0.104)$ between the cell lines. The columns with different letters $(a-d)$ indicate significant differences between the concentrations $(P=0.008)$. 


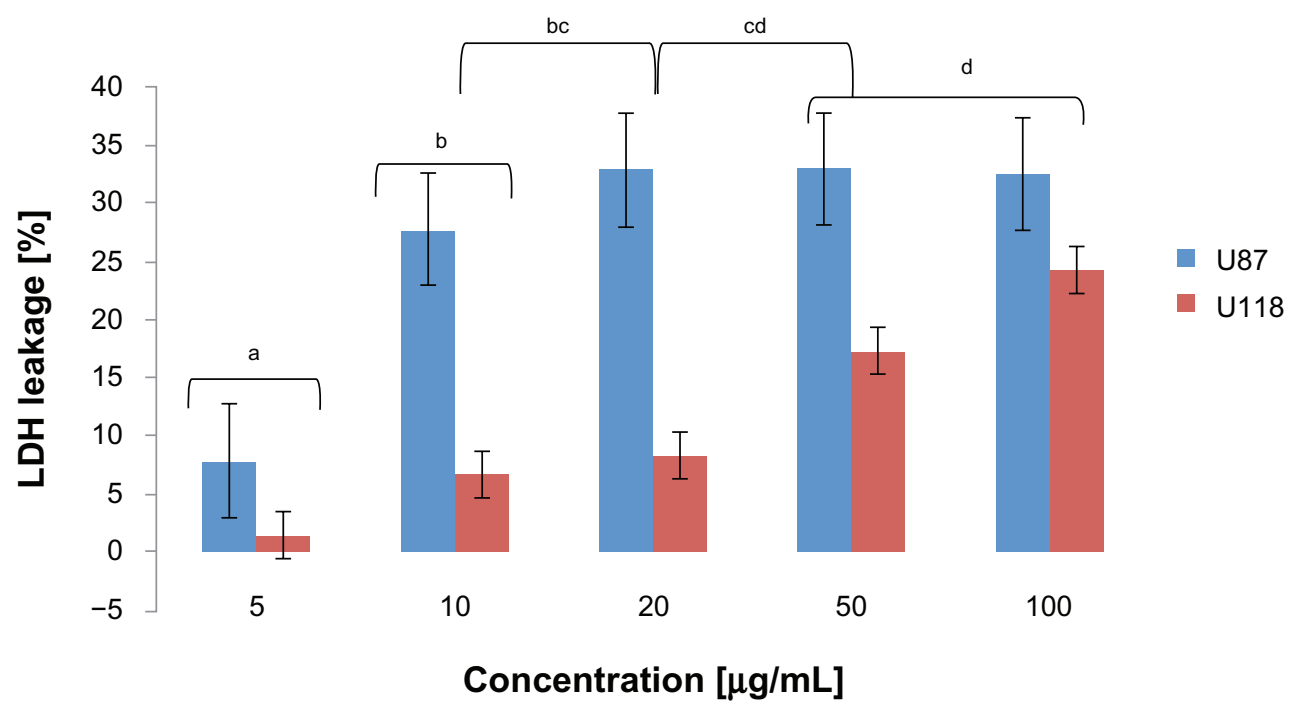

Figure 5 Effect of graphene platelets on the membrane integrity of U87 (blue) and UI I8 (red) glioma cells.

Notes: There were significant differences between the cell lines $(P=0.022)$. The columns with different letters $(a-d)$ indicate significant differences between the concentrations $(P<0.038)$.

Abbreviation: LDH, lactate dehydrogenase.

and $52 \%$ of U118 cells, which is in line with other reported results of researchers who have demonstrated the high toxicity of graphene oxide. ${ }^{14,15}$ However, there are also indications that graphene oxide has a low toxicity. When administered at low concentrations to human-derived cell lines A549 and SHSY5Y, no obvious cytotoxicity effects were observed. ${ }^{12,16-18}$ Nevertheless, it has to be kept in mind that cytotoxicity of GPs cannot be directly compared with toxicity of graphene oxide, because these materials have different physicochemical properties and consequently may act differently on living organisms. Also, the comparisons with different cell lines (A549 and SH-SY5Y) are inconclusive because their morphology and functionality are different from those of U87 and U118 cells.

Although the toxicity of GPs in the present experiment was similar in both U87 and U118 cell lines, the effect on the cell membrane was different. Significant differences were seen after analyzing the integrity of membranes in the two glioma cell lines treated with GPs, using the LDH test. Membrane integrity was disrupted to a greater extent in U87 cells than in U118 cells, even at a low GP concentration. This may be explained by the different morphology of the cell lines. The surface of U118 cells is more branched than that of U87 cells and, as such, the cell membrane is longer and the proportion of protrusions to the central body of the cells is higher. Moreover, visualization of the bio-interactions between GPs and the cells showed that the GPs had a higher affinity to the body of the cells than to the protrusions. This may explain the mechanism of toxicity, which might depend on the surface of the cell membrane. As U118 cells have more branches than U87 cells, they have less of their central body surface exposed, thus a smaller area of the total cell membrane would have been affected by the GPs. Furthermore, the localization of receptors and subcellular organelles within the central body and protrusions was different between the cell lines, which may have modified the biological effects of the GPs; this was evaluated in the second part of the study.

To explain the morphology-dependent mechanism of GP toxicity in different glioma cell lines, we investigated cell death using apoptosis and necrosis assays. The cell lines used in our experiment are characterized not only by different morphology but also by different activity of the genes involved in cell-cycle regulation and programmed cell death. The U118 cell line, in comparison to the U87, shows reduced expression of many genes, such as $p 53, p 27$, $B c l 2$, PTEN, and PARP. ${ }^{10}$ Exposure to graphene induced the process of apoptosis in both glioma cell lines but with different results: $68 \%$ in U87 cells and $99 \%$ in U118 cells. The activation of apoptosis was also observed in a study on the influence of graphene and nanotubes on the U251 glioma cell line, which was treated photothermally. ${ }^{19}$ Moreover, in our study, the level of necrosis was also different $-24 \%$ in U 87 cells and $0.2 \%$ in U118 cells. This may indicate that the response to stress caused by GPs is controlled by molecular mechanisms. Consequently, U118 cells with reduced expression of the anti-apoptotic gene $B c l 2$ and/or the suppressor gene PTEN allow for much more intense switching in the molecular mechanisms involving apoptosis. In contrast, U87 cells exhibit a strongly controlled process of apoptosis in addition to necrosis mechanisms. 
A

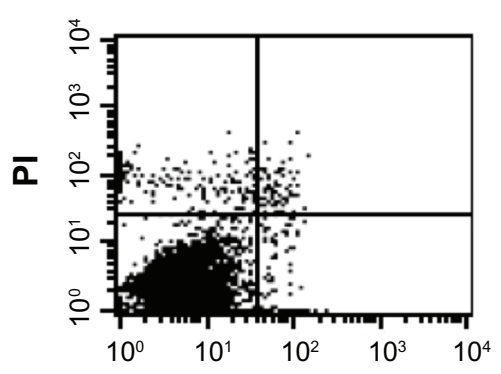

Annexin V Alexa Fluor 488
B

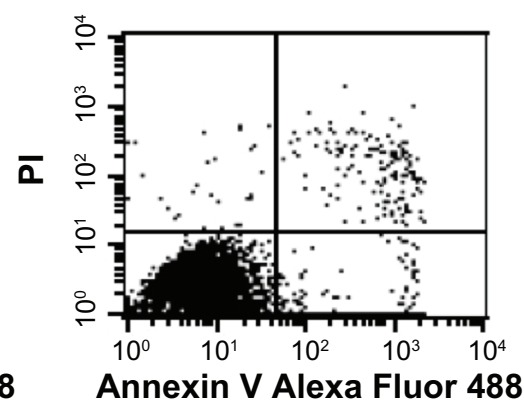

D

C

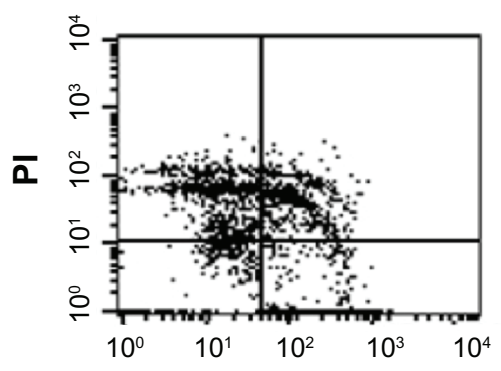

Annexin V Alexa Fluor 488

E

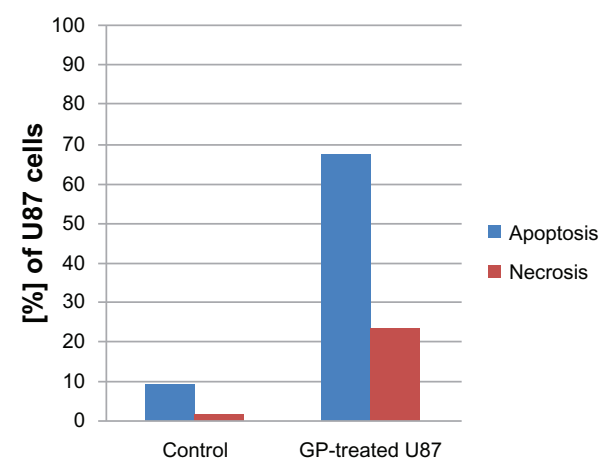

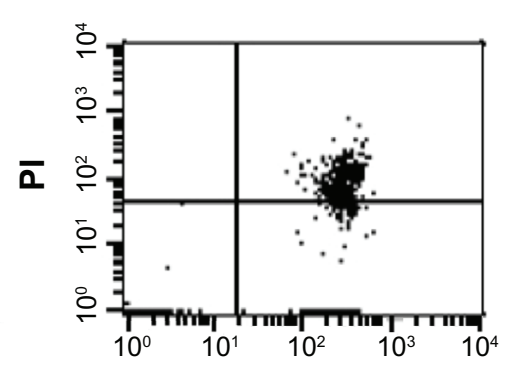

Annexin V Alexa Fluor 488

$\mathbf{F}$

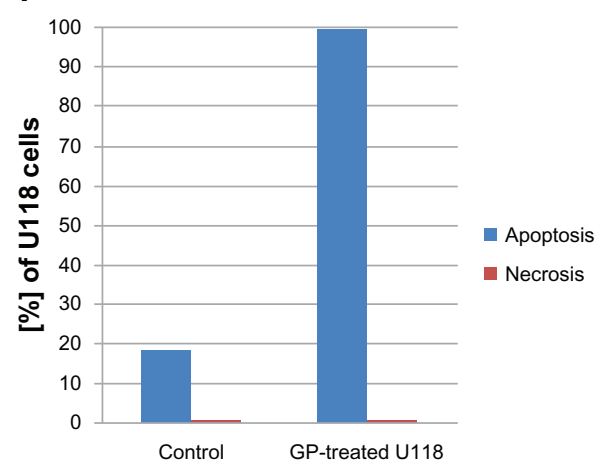

Figure 6 Annexin V-Alexa Fluor ${ }^{\circledast} 488$ and propidium iodide (PI) assay analysis. Scatter diagrams of cells exposed to $100 \mu \mathrm{L} / \mathrm{mL}$ of graphene platelets (GPs). (A) U87 control; (B) UII 8 control; (C) GP-treated U87; (D) GP-treated UI I8. Different concentrations between control and treated groups are due to unlabeled GP agglomerates. Rate of apoptosis and necrosis in U87 (E) and in UII8 (F) cells.

It has been demonstrated that graphene oxide affects not only the development of inflammation but also the activation of apoptotic cell death pathways in the respiratory system. It causes severe lung damage and leads to an increased rate of mitochondrial respiration and the generation of reactive oxygen species in lung cells. ${ }^{20,21}$ Also, in murine RAW 264.7 macrophages, graphene oxide induces cytotoxicity through the depletion of the mitochondrial membrane potential, increasing production of intracellular reactive oxygen species and triggering apoptosis. ${ }^{22}$ In the present study, graphene caused glioma cell mortality to the same degree in both U118 and U87 cell lines; however, damage to cell membranes was much greater in U87 cells, suggesting that GPs may influence mechanisms of cell death by interfering with the mitochondrial respiration system and oxidative stress.

Graphene may block the delivery of nutrients to cancer cells by adhering to cell membranes. GPs may also interact with cell membrane surface receptors and can block the transport of various substances into the cell, inducing cellular stress and apoptosis. ${ }^{23}$ The precise mechanism of apoptosis is still unknown. However, it is clear that because of a mutation of the gene $p 53$ in $\mathrm{U} 118$ cells, this gene is not involved in apoptosis activation. Furthermore, it has been shown that there are no changes in the expression of $p 53$ and its target proteins during apoptosis activation in both U118 and U87 cell lines. ${ }^{24}$ This indicates that apoptosis could occur in a manner independent of $p 53$, which suggests that there must be another mechanism 
involved. Zhu and Weiss ${ }^{25}$ have demonstrated that inactivation of mouse Hus1 protein in primary cultured cells leads to chromosomal instability during DNA replication, triggering apoptosis and impairing proliferation through $p 53$-independent mechanisms. In the present case, it is possible that Hus1 protein was blocked, causing apoptosis without activation of $p 53$.

The present results are preliminary and follow-up research to elucidate the molecular mechanisms involved in the interactions between GPs and cells is necessary. At this stage, the results indicate that the contact between GPs and U87 and U118 cell membranes may be the key cause of GP toxicity. Consequently, the morphology of different glioma cells, the molecular status of cell lines, and the GP concentration may act together to regulate the biological response of glioma cells to GPs.

\section{Conclusion}

The results demonstrate that cytotoxicity of GPs on glioma cells increases with increasing GP concentrations from 10 to $100 \mu \mathrm{g} / \mathrm{mL}$. However, GPs only activate apoptosis without inducing necrosis in the U118 cell line, indicating the potential applicability of GPs in cancer therapy.

\section{Acknowledgments}

This work was supported by the grant NCN 2011/03/B/ NZ9/03387. This report is a part of Slawomir Jaworski's $\mathrm{PhD}$ thesis.

\section{Disclosure}

The authors declare no conflicts of interest in this work.

\section{References}

1. Westermark B. Glioblastoma - a moving target. Ups J Med Sci. 2012; 117(2):251-256.

2. Cloughesy T. The impact of recent data on the optimization of standards of care in newly diagnosed glioblastoma. Semin Oncol. 2011;38 Suppl 4: S11-S20.

3. Debatin KM. Apoptosis pathways in cancer and cancer therapy. Cancer Immunol Immunother. 2004;53(3):153-159.

4. Tabunoki H, Saito N, Suwanborirux K, Charupant K, Satoh J. Molecular network profiling of U373MG human glioblastoma cells following induction of apoptosis by novel marine-derived anti-cancer 1,2,3,4tetrahydroisoquinoline alkaloids. Cancer Cell Int. 2011;12(1):14.

5. An YL, Nie F, Wang ZY, Zhang DS. Preparation and characterization of realgar nanoparticles and their inhibitory effect on rat glioma cells. Int J Nanomedicine. 2011;6:3187-3194.

International Journal of Nanomedicine

\section{Publish your work in this journal}

The International Journal of Nanomedicine is an international, peerreviewed journal focusing on the application of nanotechnology in diagnostics, therapeutics, and drug delivery systems throughout the biomedical field. This journal is indexed on PubMed Central, MedLine, CAS, SciSearch ${ }^{\circledR}$, Current Contents ${ }^{\circledR} /$ Clinical Medicine,
6. Grodzik M, Sawosz E, Wierzbicki M, et al. Nanoparticles of carbon allotropes inhibit glioblastoma multiforme angiogenesis in ovo. Int $J$ Nanomedicine. 2011;6:3041-3048.

7. Aillon KL, Xie Y, El-Gendy N, Berkland CJ, Forrest ML. Effects of nanomaterial physicochemical properties on in vivo toxicity. Adv Drug Deliv Rev. 2009;61(6):457-466.

8. Geim AK, Novoselov KS. The rise of graphene. Nat Mater. 2007;6(3): 183-191.

9. Yang K, Feng L, Shi X, Liu Z. Nano-graphene in biomedicine: theranostic applications. Chem Soc Rev. 2013;42(2):530-547.

10. Strakova N, Ehrmann J, Dzubak P, Bouchal J, Kolar Z. The synthetic ligand of peroxisome proliferator-activated receptor-gamma ciglitazone affects human glioblastoma cell lines. J Pharmacol Exp Ther. 2004; 309(3):1239-1247.

11. Zhang LM, Xia JG, Zhao QW, et al. Functional graphene oxide as a nanocarrier for controlled loading and targeted delivery of mixed anticancer drugs. Small. 2010;6(4):537-544.

12. Chang Y, Yang ST, Liu JH, et al. In vitro toxicity evaluation of graphene oxide on A549 cells. Toxicology Lett. 2011;200(3):201-210.

13. Chwalibog A, Sawosz E, Hotowy A, et al. Visualization of interaction between inorganic nanoparticles and bacteria or fungi. Int J Nanomedicine. 2010;5:1085-1094.

14. Wang K, Ruan J, Song H, et al. Biocompatibility of graphene oxide. Nanoscale Res Lett. 2011;6:8.

15. Agarwal S, Zhou X, Ye F, et al. Interfacing live cells with nanocarbon substrates. Langmuir. 2010;26(4):2244-2247.

16. Liu Z, Robinson JT, Sun X, Dai H. PEGylated nanographene oxide for delivery of water-insoluble cancer drugs. JAm Chem Soc. 2008;130(33): 10876-10877.

17. Liu JH, Anilkumar P, Cao L, et al. Cytotoxity evaluations of fluorescent carbon nanoparticles. Nano Life. 2010;1(2):153-161.

18. Lv M, Zhang Y, Liang L, et al. Effect of graphene oxide on undifferentiated and retinoic acid-differentiated SH-SY5Y cells line. Nanoscale. 2012;4(13):3861-3866.

19. Markovic ZM, Harhaji-Trajkovic LM, Todorovic-Markovic BM, et al. In vitro comparison of the photothermal anticancer activity of graphene nanoparticles and carbon nanotubes. Biomaterials. 2011;32(4): $1121-1129$.

20. Schinwald A, Murphy FA, Jones A, MacNee W, Donaldson K. Graphene-based nanoplatelets: a new risk to the respiratory system as a consequence of their unusual aerodynamic properties. ACS Nano. 2012;6(1):736-746.

21. Duch MC, Budinger GR, Liang YT, et al. Minimizing oxidation and stable nanoscale dispersion improves the biocompatibility of graphene in the lung. Nano Lett. 2011;11(12):5201-5207.

22. Li Y, Liu Y, Fu Y, et al. The triggering of apoptosis in macrophages by pristine graphene through the MAPK and TGF-beta signaling pathways. Biomaterials. 2012;33(2):402-411.

23. Guo L, Von Dem Bussche A, Buechner M, Yan A, Kane AB, Hurt RH. Adsorption of essential micronutrients by carbon nanotubes and the implications for nanotoxicity testing. Small. 2008;4(6):721-727.

24. Stockmann-Juvala H, Naarala J, Loikkanen J, Vähäkangas K, Savolainen K. Fumonisin B1-induced apoptosis in neuroblastoma, glioblastoma and hypothalamic cell lines. Toxicology. 2006;225(2-3):234-241.

25. Zhu M, Weiss RS. Increased common fragile site expression, cell proliferation defects, and apoptosis following conditional inactivation of mouse Hus 1 in primary cultured cells. Mol Biol Cell. 2007;18(3):1044-1055.

\section{Dovepress}

Journal Citation Reports/Science Edition, EMBase, Scopus and the Elsevier Bibliographic databases. The manuscript management system is completely online and includes a very quick and fair peer-review system, which is all easy to use. Visit http://www.dovepress.com/ testimonials.php to read real quotes from published authors. 